\title{
CLINICAL TRIALS WATCH
}

\begin{tabular}{|c|c|c|c|c|c|c|c|c|}
\hline \multirow[t]{2}{*}{ Total number of trials registered } & \multicolumn{8}{|c|}{ Clinical trials.gov, $\mathrm{N}=1040$} \\
\hline & Year missing & $2003 \&$ prior & 2004 & 2005 & 2006 & 2007 & 2008 & Jun-09 \\
\hline Number of trials & 21 & 103 & 79 & 118 & 183 & 226 & 225 & 85 \\
\hline \multicolumn{9}{|l|}{ Recruitment status } \\
\hline Active, not recruiting & 3 & 18 & 8 & 16 & 41 & 44 & 33 & \\
\hline Completed & 8 & 68 & 57 & 63 & 81 & 67 & 23 & \\
\hline Enrolling by invitation & & & & & 1 & 3 & 8 & 2 \\
\hline Not yet recruiting & 2 & & & & 2 & 5 & 4 & 27 \\
\hline Recruiting & 3 & 14 & 7 & 26 & 50 & 90 & 154 & 54 \\
\hline Suspended & & & & & & 4 & & \\
\hline Temporarily not available & & & & & & & & 1 \\
\hline Terminated & & 3 & 7 & 13 & 8 & 12 & 2 & \\
\hline Withdrawn & & & & & & 1 & 1 & 1 \\
\hline Recruitment status not known & 5 & & & & & & & \\
\hline Total & 21 & 103 & 79 & 118 & 183 & 226 & 225 & 85 \\
\hline \multicolumn{9}{|l|}{ Type of study } \\
\hline Behavioural & 1 & 6 & 3 & 2 & 3 & 4 & 3 & 1 \\
\hline Device & & 2 & 1 & 6 & 10 & 12 & 8 & 2 \\
\hline Dietary supplement & & 1 & & 2 & & 2 & 7 & 2 \\
\hline Drug & 10 & 70 & 65 & 87 & 146 & 176 & 173 & 59 \\
\hline Procedure & 3 & 7 & 3 & 7 & 8 & 4 & 5 & 6 \\
\hline Radiation & & 1 & & 3 & & 1 & 1 & \\
\hline Biological & & 3 & 1 & 5 & 10 & 20 & 17 & 9 \\
\hline Gene transfer & & & 1 & & & & & \\
\hline Other & & 4 & 1 & 2 & 2 & 4 & 5 & 3 \\
\hline Not given & 7 & 9 & 4 & 4 & 4 & 3 & 6 & 3 \\
\hline Total & 21 & 103 & 79 & 118 & 183 & 226 & 225 & 85 \\
\hline \multicolumn{9}{|l|}{ Disease conditions } \\
\hline Bacterial infections, intestinal infections, STDs & 7 & 25 & 6 & 20 & 24 & 31 & 28 & 11 \\
\hline Neoplasms & 5 & 23 & 14 & 24 & 43 & 44 & 44 & 12 \\
\hline \multicolumn{9}{|l|}{ Endocrine, nutritional, and metabolic } \\
\hline Mental and behavioural diseases & & 2 & 5 & 9 & 4 & 12 & 7 & 2 \\
\hline Diseases of the nervous system & & & 9 & 4 & 11 & 20 & 11 & 2 \\
\hline Diseases of the circulatory system & & 7 & 8 & 14 & 19 & 29 & 28 & 13 \\
\hline Diseases of the respiratory system & & 9 & 6 & 4 & 7 & 6 & 6 & 8 \\
\hline Diseases of the digestive system & & 4 & 4 & 6 & 8 & 10 & 3 & 6 \\
\hline Diabetes & & 6 & 4 & 9 & 28 & 17 & 46 & 16 \\
\hline Double disease condition & 1 & 10 & 6 & 7 & 4 & 16 & 5 & 3 \\
\hline Other & 3 & 17 & 17 & 21 & 35 & 41 & 47 & 12 \\
\hline Disease conditions not known & 5 & & & & & & & \\
\hline Total & 21 & 103 & 79 & 118 & 183 & 226 & 225 & 85 \\
\hline \multicolumn{9}{|l|}{ Sponsor nationality } \\
\hline Indian & 2 & 23 & 19 & 26 & 34 & 32 & 34 & 20 \\
\hline Non-Indian & 13 & 67 & 54 & 81 & 139 & 183 & 180 & 61 \\
\hline Indian and Non-Indian & 1 & 13 & 6 & 11 & 10 & 11 & 11 & 4 \\
\hline Sponsor nationality not known & 5 & & & & & & & \\
\hline Total & 21 & 103 & 79 & 118 & 183 & 226 & 225 & 85 \\
\hline \multicolumn{9}{|l|}{ Sponsor ownership } \\
\hline Public & 8 & 28 & 12 & 16 & 21 & 17 & 21 & 12 \\
\hline Private & 5 & 54 & 55 & 72 & 148 & 185 & 188 & 67 \\
\hline Non-profit & & 4 & 5 & 10 & 3 & 6 & 4 & \\
\hline Public, private & 1 & 3 & 1 & 5 & 2 & 9 & 3 & 2 \\
\hline Non-profit, public & & 2 & 1 & 4 & 1 & 1 & 1 & \\
\hline Non-profit, private & & 1 & & 1 & 1 & 1 & 2 & \\
\hline Mixed & 2 & 11 & 5 & 10 & 7 & 7 & 6 & 4 \\
\hline \multicolumn{9}{|l|}{ Individual investigator } \\
\hline \multicolumn{9}{|l|}{ Individual investigator, public } \\
\hline \multicolumn{9}{|l|}{ Individual investigator, non-profit } \\
\hline Sponsor ownership not known & 5 & & & & & & & \\
\hline Total & 21 & 103 & 79 & 118 & 183 & 226 & 225 & 85 \\
\hline \multicolumn{9}{|l|}{ Sponsor profile } \\
\hline Institution/Agency & 11 & 59 & 28 & 45 & 47 & 46 & 43 & 19 \\
\hline Pharma & 5 & 43 & 49 & 68 & 136 & 177 & 178 & 64 \\
\hline Both & & 1 & 2 & 5 & & 3 & 4 & 2 \\
\hline Sponsor profile not known & 5 & & & & & & & \\
\hline Total & 21 & 103 & 79 & 118 & 183 & 226 & 225 & 85 \\
\hline
\end{tabular}




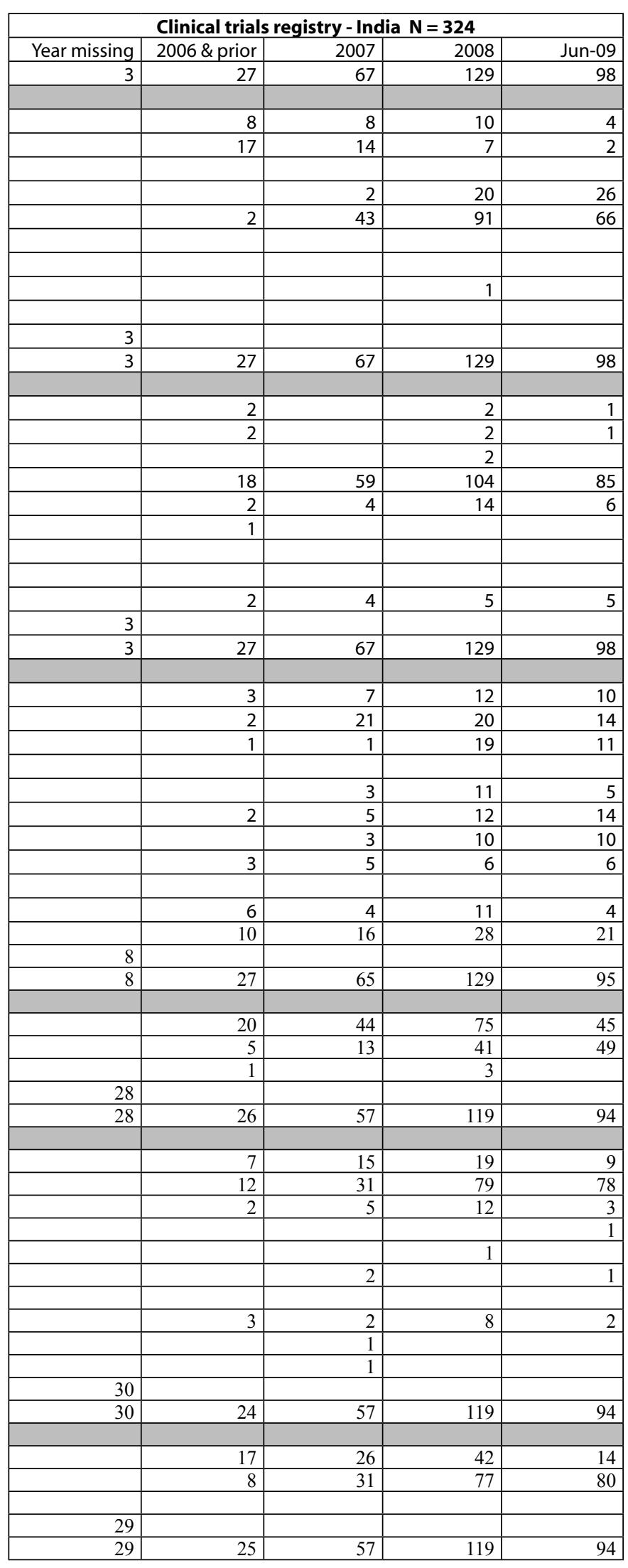

\section{Clinical Trials Watch}

The launch of the Clinical Trials Registry-India (CTR-I) provides an opportunity for one-point registration and tracking of clinical research activity in India. However, this resource has remained unexplored ever since the launch of CTR-I on July 20, 2007.

The objective of this new column, Clinical Trials Watch, is to employ CTR-I for regular monitoring of clinical research activity in India. It will therefore publish information on select indicators extracted from CTR-I on a regular basis.

Clinical Trials Watch will also publish parallel information on Indian clinical trials extracted from www.clinicaltrials.gov, a registry managed by the National Library of Medicine at the United States National Institutes of Health. This information is being included to broaden the database for monitoring clinical research in India.

We also hope that publishing parallel indicators from a relatively more established registry enables a comparative evaluation of the functioning and operational aspects of CTRI. With the current Drugs Controller General of India (DCGI) mandating registration of all clinical trials, it may be only a matter of time before the registration of trials catches up on CTR-I. That however will be an issue to examine for the next factsheet of Clinical Trials Watch, which will appear in the April 2010 issue of IJME.

\section{Methods}

For clinicaltrials.gov, a search was conducted for all trials with the keyword "India".This yielded 1,040 search results on June 15, 2009. The results were downloaded from www.clinicaltrials.gov in excel and $\mathrm{xml}$ format. The excel spreadsheet of 1,040 clinical trials, automatically generated from the website, contained the following fields in the columns: National Clinical Trials Identifier (NCT ID); brief study title; recruitment status; disease conditions; intervention type; sponsor type; phases; study start date and study design. The $\mathrm{xml}$ files contained the same fields but also contained many text-heavy fields that included study objectives, rationale, inclusion and exclusion criteria, disease characteristics and study locations. From the xml files, a second excel spreadsheet was generated by extracting only the NCT ID, study location, city and state information. The data from the two excel spreadsheets were merged.

The Indian registry yielded 324 registered trials on June 30, 2009. Trial information pertaining to each registered clinical trial was manually exported into an excel spreadsheet using a template. The fields of information exported were CTR-I ID, brief study title, study status, trial location, ethics committee details, sponsor, disease condition, trial start date, DCGI approval and study type. 


\begin{tabular}{|c|c|c|c|c|c|c|c|c|}
\hline & Year missing & 2003 \& prior & 2004 & 2005 & 2006 & 2007 & 2008 & 2009 \\
\hline \multicolumn{9}{|l|}{ Phases } \\
\hline 0 & & & & & & & 1 & \\
\hline I & 1 & 6 & 3 & 3 & 5 & 4 & 7 & 3 \\
\hline II & 3 & 11 & 11 & 26 & 28 & 43 & 41 & 12 \\
\hline III & 5 & 46 & 34 & 54 & 105 & 123 & 120 & 28 \\
\hline IV & 1 & 11 & 10 & 13 & 11 & 18 & 14 & 19 \\
\hline $\mathrm{I} / \mathrm{II}$ & & 1 & 3 & 1 & 1 & 7 & 7 & 5 \\
\hline II/III & 1 & 5 & 3 & 4 & 7 & 9 & 8 & 3 \\
\hline \multicolumn{9}{|l|}{ III/IV } \\
\hline \multicolumn{9}{|l|}{ not applicable } \\
\hline Not given & 10 & 23 & 15 & 17 & 26 & 22 & 27 & 15 \\
\hline Total & 21 & 103 & 79 & 118 & 183 & 226 & 225 & 85 \\
\hline \multicolumn{9}{|l|}{ Sampling } \\
\hline Cross sectional & & & & & & 1 & & \\
\hline Non-randomised & 3 & 6 & 11 & 15 & 21 & 29 & 18 & 7 \\
\hline Prospective & & 2 & 2 & 6 & 9 & 3 & 10 & 11 \\
\hline Randomised & 11 & 80 & 61 & 92 & 148 & 185 & 170 & 57 \\
\hline Retrospective & & & 1 & & & & & \\
\hline Convenience & & 1 & 1 & & & & & \\
\hline Defined population & & 1 & 2 & 1 & 1 & & & \\
\hline \multicolumn{9}{|l|}{ Cluster } \\
\hline \multicolumn{9}{|l|}{ Other } \\
\hline Not given & 7 & 13 & 1 & 4 & 4 & 8 & 27 & 10 \\
\hline Total & 21 & 103 & 79 & 118 & 183 & 226 & 225 & 85 \\
\hline \multicolumn{9}{|l|}{ Assignment } \\
\hline Crossover & & 6 & 3 & 4 & 12 & 5 & 4 & 4 \\
\hline Factorial & & 7 & 1 & 5 & 3 & 1 & 3 & \\
\hline Parallel & 9 & 61 & 51 & 81 & 134 & 183 & 171 & 55 \\
\hline Single group & 5 & 10 & 17 & 18 & 24 & 32 & 33 & 14 \\
\hline \multicolumn{9}{|l|}{ Other } \\
\hline Not given & 7 & 19 & 7 & 10 & 10 & 5 & 14 & 12 \\
\hline Total & 21 & 103 & 79 & 118 & 183 & 226 & 225 & 85 \\
\hline \multicolumn{9}{|l|}{ Control } \\
\hline Active & 5 & 44 & 22 & 40 & 71 & 79 & 55 & 16 \\
\hline Case control & & & & 1 & & 3 & 4 & 2 \\
\hline Cohort & & 1 & 2 & 3 & 7 & & 3 & 7 \\
\hline Cross sectional & & 1 & 2 & 1 & 1 & 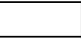 & 1 & \\
\hline Dose comparison & & 4 & 3 & 1 & 4 & 7 & 5 & 1 \\
\hline Historical & & & & 1 & 3 & 4 & 1 & \\
\hline Longitudinal & & 1 & 1 & & & & & \\
\hline Placebo & 3 & 18 & 23 & 33 & 45 & 50 & 59 & 12 \\
\hline Uncontrolled & 3 & 4 & 10 & 11 & 13 & 15 & 14 & 4 \\
\hline \multicolumn{9}{|l|}{ Multi-arm } \\
\hline \multicolumn{9}{|l|}{ Crossover } \\
\hline Other & & & & & & & & \\
\hline Not given & 10 & 30 & 16 & 27 & 39 & 68 & 83 & 43 \\
\hline Total & 21 & 103 & 79 & 118 & 183 & 226 & 225 & 85 \\
\hline Total number of drug trial settings & & & $\mathrm{N}=38 \varepsilon$ & & & & & \\
\hline & & 2003 \& prior & 2004 & 2005 & 2006 & 2007 & 2008 & Jun-09 \\
\hline Number of drug trial settings & 29 & 231 & 229 & 443 & 854 & 904 & 994 & 200 \\
\hline Total number of drug trials & & & $\mathrm{N}=78$ & & & & & \\
\hline & & 2003 \& prior & 2004 & 2005 & 2006 & 2007 & 2008 & Jun-09 \\
\hline Number of drug trials & 10 & 70 & 65 & 87 & 146 & 176 & 173 & 59 \\
\hline Top drug trial settings by cities & & & & & & & & \\
\hline Mumbai & 2 & 33 & 31 & 54 & 101 & 99 & 103 & 12 \\
\hline Bangalore & 2 & 25 & 34 & 57 & 83 & 99 & 118 & 15 \\
\hline Delhi & 6 & 29 & 27 & 52 & 58 & 83 & 85 & 15 \\
\hline Hyderabad & 1 & 21 & 27 & 47 & 79 & 81 & 73 & 16 \\
\hline Pune & 3 & 13 & 15 & 28 & 71 & 71 & 73 & 13 \\
\hline Others & 15 & 110 & 95 & 205 & 462 & 471 & 542 & 129 \\
\hline Top drug trial settings by states & & & & & & & & \\
\hline Maharashtra & 5 & 50 & 46 & 87 & 206 & 197 & 226 & 37 \\
\hline Karnataka & 2 & 29 & 42 & 76 & 122 & 141 & 175 & 23 \\
\hline Tamil Nadu & 5 & 33 & 25 & 56 & 100 & 90 & 105 & 27 \\
\hline Andhra Pradesh & 1 & 23 & 28 & 60 & 103 & 110 & 100 & 21 \\
\hline Delhi & 6 & 29 & 27 & 52 & 58 & 83 & 85 & 15 \\
\hline Others & 10 & 67 & 61 & 112 & 265 & 283 & 303 & 77 \\
\hline
\end{tabular}




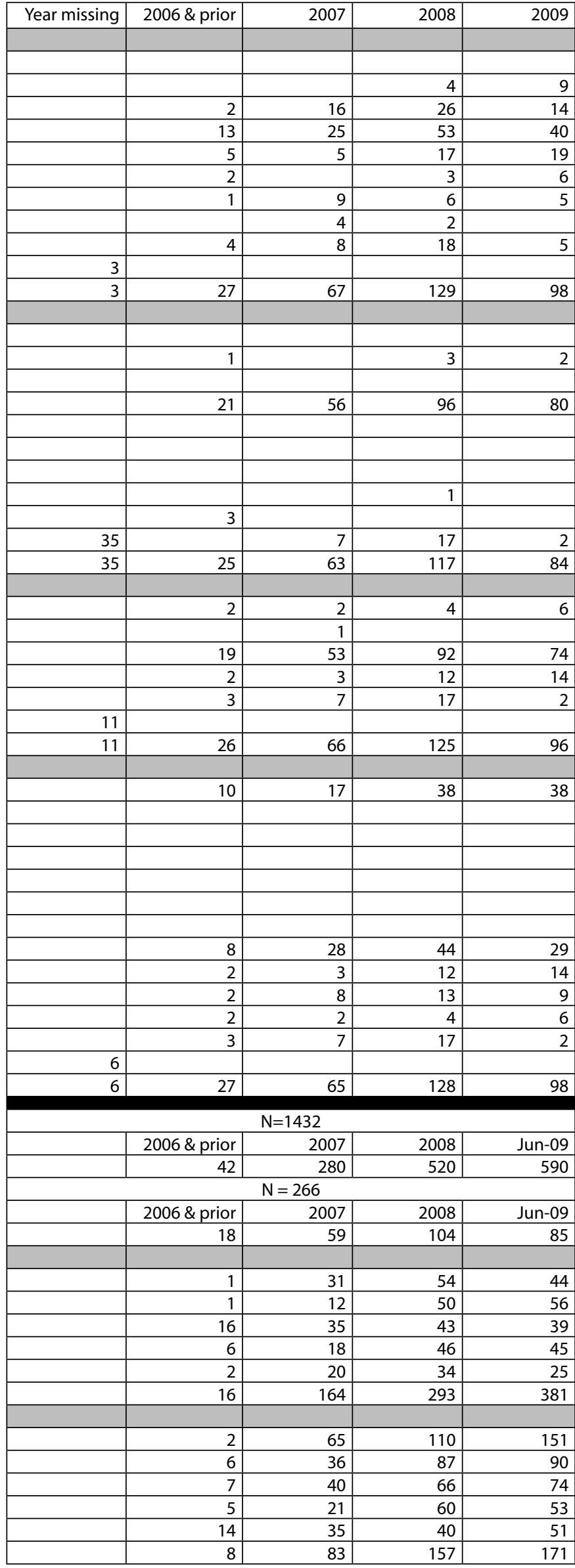

All data were then exported to SPSS for analysis. Categories presented in the tables are as given in the original datasets. In some cases, the variables were recoded to ensure comparability across two data sets. Details of recoded variables are given in the notes.

This factsheet has been prepared at the Centre for Studies in Ethics and Rights, Mumbai. CSER thanks Prof Roger Jeffery, department of sociology, University of Edinburgh, UK for making available financial support for the project.

The authors acknowledge Amar Jesani and Neha Madhiwalla for their guidance in the preparation of this column.

\section{Prepared by Sachin Nikarge sachinikarge@yahoo.com and Divya Pamnani pamnani.divya@gmail.com}

\section{Notes: recoded variables}

Year: CTR-I provides a record of the last date on which the study was verified, the date on which the study was updated and the date of first enrolment for each trial. The date of first enrolment was coded as the 'year' for each trial. Clinicaltrials.gov provides a record of the study start date, the date on which information was first received on the registry, as well as the date of trial completion, "last updated", and "last verified" dates. The study start date was coded as the 'year' for each trial.

As the numbers were very small, trials starting in the year 2003 or earlier were combined into one category for the trials listed in Clinicaltrials.gov. Similarly, trials starting in 2006 or earlier were combined into one category for the trials listed in CTR-I.

Disease conditions: Disease conditions were coded according to the 10th revision of the World Health Organization (WHO) International Classification of Diseases (ICD 10). There were 18 categories in the ICD 10, including diseases of the nervous system, circulatory system and digestive system. To these categories, a new category, "double disease conditions", was added to include combinations of the disease conditions involved in the trial. After running the frequencies for all disease conditions, only the prominent categories were chosen for representation. The less significant categories were clubbed as a separate category named "other."

Type of study: In Clinicaltrials.gov, all trials were pre-coded according to the type of study as "drug", "behavioural," "device", "procedure", "radiation", and "other". The same classification was used to recode the trials listed on CTR-I after a careful reading of each study title.

Sponsors were categorised as: Indian and non-Indian; private, public and non-profit; and, lastly, institution/agency and pharmaceutical company.

Drug trial setting: This refers to the city or state where the site of a drug trial (as defined in "type of study") was located. An analysis of the locations of trials was conducted only for drug trials. 